
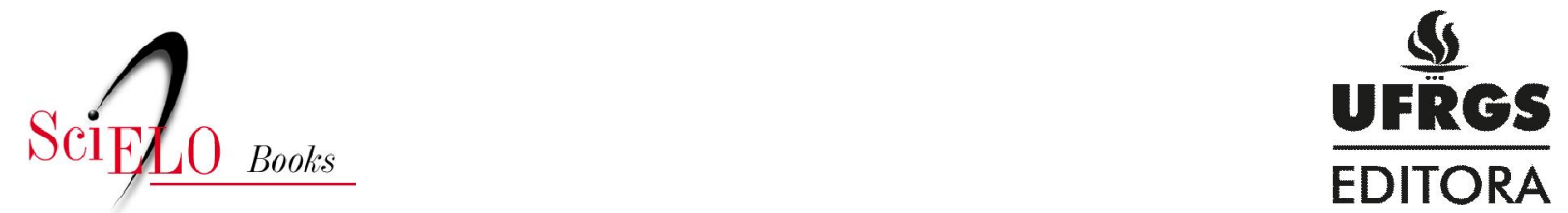

\title{
Teoria neoschumpeteriana e desenvolvimento econômico
}

\author{
Ricardo Dathein
}

SciELO Books / SciELO Livros / SciELO Libros

DATHEIN, R., org. Teoria neoschumpeteriana e desenvolvimento econômico. In:

Desenvolvimentismo: o conceito, as bases teóricas e as políticas [online]. Porto Alegre: Editora da UFRGS, 2003. Estudos e pesquisas IEPE series, pp. 193-222. ISBN 978-85-386-0382-5. Available from doi: $10.7476 / 9788538603825$. Also available in ePUB from:

http://books.scielo.org/id/8m95t/epub/dathein-9788538603825.epub.

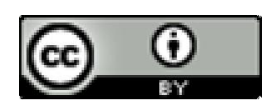

All the contents of this work, except where otherwise noted, is licensed under a Creative Commons Attribution 4.0 International license.

Todo o conteúdo deste trabalho, exceto quando houver ressalva, é publicado sob a licença Creative Commons Atribição $\underline{4.0}$.

Todo el contenido de esta obra, excepto donde se indique lo contrario, está bajo licencia de la licencia $\underline{\text { Creative Commons }}$ $\underline{\text { Reconocimento } 4.0 \text {. }}$ 


\section{Teoria neoschumpeteriana e desenvolvimento econômico'}

Ricardo Dathein

\section{Introdução}

A corrente teórica neoschumpeteriana tem avançado substancialmente o pensamento econômico sobre desenvolvimento. Esta teoria é apropriada para análises desenvolvimentistas e, além disso, é adequada para uso como instrumento de elaboração de políticas econômicas, podendo ser adaptada para casos de países não desenvolvidos, como o Brasil, o que tem sido feito por muitos autores internacionais e brasileiros.

A visão teórica de Schumpeter diverge de maneira fundamental da concepção neoclássica, em sua época, com seu foco na dinâmica endógena ao sistema econômico e no poder de mercado como meta e fonte das ações empresariais. Nesse sentido, é, concomitantemente, em suas duas vertentes, uma teoria sobre desenvolvimento econômico e sobre a ação microeconômica das empresas e dos indivíduos.

A teoria schumpeteriana teve um renascimento nas últimas décadas do século XX. Isso pode ter ocorrido devido à revolução tecnológica desse período e ao maior reconhecimento da importância da dinâmica das inovações e das flutuações econômicas de longo prazo (Acs, 2007, p. 97; Freeman, 2007). Essa teoria neoschumpeteriana ou evolucionária ${ }^{2}$, que

\footnotetext{
${ }^{1}$ Este capítulo é uma versão de pesquisa realizada com apoio do IPEA no âmbito do projeto "A dimensão produtivo-tecnológica nas teorias do desenvolvimento econômico e suas decorrências normativas: em busca de fundamentos teóricos para as políticas industriais e de CT\&I".

${ }^{2}$ Adotam-se aqui os termos teoria neoschumpeteriana e teoria evolucionária como sinônimos, distinguindo-os do termo evolucionista, que representa uma abordagem mais ampla em termos teóricos (Nelson e Winter, 1982; Conceição, 2008).
} 
se desenvolve a partir dos anos 1980, é formada por um conjunto de contribuições de modelos formais e análises apreciativas ou históricas não necessariamente formando um todo uniforme.

Outra característica importante desse pensamento evolucionário é que, apesar de Schumpeter poder ser caracterizado como um "liberal devoto do livre mercado" (Fagerberg, 2000, p. 99), sua teoria pode ser muito útil como base para políticas econômicas, tendo em vista a forma como entende o funcionamento da economia, dos determinantes do crescimento e de suas instituições.

Além disso, há uma aproximação entre o pensamento neoschumpeteriano ou evolucionário com o neoinstitucionalista, se complementando e formando uma abordagem "institucionalista-evolucionária", a qual analisa a coevolução de tecnologias, estruturas econômicas e instituições (Nelson, 2002).

O objetivo fundamental deste capítulo é analisar as diferentes contribuições teóricas da escola neoschumpeteriana. O capítulo está estruturado em quatro seções. A seção um analisa as principais concepções da teoria evolucionária, ressaltando a lógica econômica das firmas e as interrelações da estrutura do mercado com as inovações no âmbito microeconômico. Além disso, examina o tema do desenvolvimento econômico, com destaque para as conexões entre o processo de aprendizado e a acumulação de capacitações e para o conceito de "eficiência schumpeteriana”. A seção dois apresenta uma discussão sobre Sistemas de Inovação (SIs), a partir da qual se explica a dinâmica da mudança econômica (os determinantes das invenções, inovações e sua difusão, absorção e uso) em suas relações tecnológicas, organizacionais e institucionais. A seção três trata dos paradigmas tecnoeconômicos e dos ciclos de longo prazo, levando em conta que o desenvolvimento não é linear no tempo e que existem processos de convergência e divergência econômica entre países. A seção quatro, por fim, considera as relações entre tecnologia e inserção econômica internacional, com suas elaborações teóricas evolucionárias sobre gap tecnológico e o papel dos investimentos externos diretos.

\section{Teoria evolucionária}

Fagerberg (2000) argumenta que, em Schumpeter, o fator determinante do desenvolvimento (ou o que "dirige o crescimento") não seria a acu- 
mulação de capital ou a "mecanização" (como aparece nas teorias clássica, marxista, neoclássica e keynesiana), mas as inovações, como um processo que provoca mudança qualitativa na economia. O que mede a acumulação seria, de certa forma, apenas uma descrição do crescimento econômico. As inovações, entretanto, explicariam a causa da acumulação. Segundo Fagerberg, esse destaque só (re)aparece tão recentemente nas teorias econômicas devido ao fato de que a indústria baseada na ciência e o processo de pesquisa e desenvolvimento organizado são muito novos.

A partir do modelo schumpeteriano, surge uma análise dos microfundamentos das inovações (uma microeconomia evolucionária), com pressupostos de incerteza e de diferenciação da importância dessas inovações (incrementais ou radicais), assim como uma teoria sobre o desenvolvimento econômico (Verspagen, 2005, p. 493). Nessa passagem da micro para a macro, a órbita meso adquire relevância, não havendo uma lógica de agregação do micro para a macro, tendo em vista as mudanças qualitativas na estrutura econômica (Dopfer, 2007, p. 65) e a característica heterogênea dos agentes econômicos, o que justamente é fundamental para explicar os estímulos às inovações (Fagerberg, 2000, p. 100).

Nelson e Winter (1982, p. 303 e 396) afirmam que a teoria neoclássica é inadequada para a análise da mudança técnica e não fornece meios de conciliar as abordagens de crescimento com o nível microeconômico. A partir dessa crítica, os dois autores elaboraram uma teoria evolucionária do crescimento econômico, do comportamento da firma e da dinâmica da concorrência e sobre a lógica das políticas públicas.

Nelson (1996) caracteriza o capitalismo como um "motor de progresso", sendo o avanço técnico um processo cultural $^{3}$ (não biológico) evolucionário. Nesse processo, ocorrem desperdícios e redundância (pois não há coordenação), com perdas de economias de escala e de escopo na atividade de Pesquisa e Desenvolvimento (P\&D). Segundo Nelson, os resultados nem sempre são os melhores, e P\&D com alto valor social pode não ser realizada, tendo em vista o objetivo de lucro. Nesse sentido, o planejamento é uma possibilidade. Nelson, no entanto, argumenta que o resultado dessa atividade inovadora no mercado tem tido resultados "notáveis" e que o planejamento do progresso técnico é

${ }^{3}$ A tecnologia pode dar "grandes saltos" e não é aleatória (Nelson, 1996, p. 92). 
difícil, tendo em vista sua incerteza inerente sobre como melhorar as tecnologias, quais os caminhos alternativos e por que existe a necessidade de se explorarem diferentes possibilidades. Assim, a competição definiria um caminho viável. Apesar do papel do governo e da coordenação e planejamento terem aumentado, a rivalidade continuaria sendo a regra. Entre as definições ex post (mesmo com desperdícios) sobre o que e como produzir e a coordenação ex ante, a primeira continuaria sendo melhor, tendo em vista as virtudes do manuseio experimental (Nelson, 1996, p. 89-96 e 133-139).

\subsection{Bases da microeconomia schumpeteriana}

As firmas possuem aptidões e procedimentos de decisão, e "buscam" melhores maneiras de "fazer as coisas" em um ambiente de seleção (mercado) que é parcialmente endógeno (Nelson; Winter, 1982, p. 304). Por outro lado, em termos microeconômicos, a dinâmica da estrutura do mercado é fundamental. ${ }^{4} \mathrm{O}$ crescimento confere vantagens às firmas, o que facilita seu desempenho futuro (quanto maior seu tamanho, maior sua capacidade de apropriação dos retornos positivos de seus investimentos em P\&D, segundo Nelson e Winter (1982, p. 497)), assim como o declínio tende a se ampliar. Além disso, existem vantagens do pioneirismo (que podem ser mais importantes do que os direitos de propriedade, dependendo do setor), tendo em vista que a imitação é cara, consome tempo, o aprendizado ocorre na linha de produção, competências especiais são de difícil transferência e as tecnologias são cumulativas no tempo (Nelson, 1996, p. 108-111). Esse processo tende a gerar concentração. No entanto, as inovações tendem a gerar monopólios apenas temporários, pois estes, ao produzirem maiores lucros, provocam um efeito de imitação e de difusão, o que tende a eliminar o lucro extraordinário com o aumento da concorrência. Essa dinâmica estimula novas inovações, e assim indefinidamente. Isso depende da escala necessária na entrada e do nível tecnológico dos entrantes. $\mathrm{Ou}$ seja, a estrutura do setor e o desempenho inovador das firmas são interdependentes (Nelson; Winter, 1982, p. 465-9).

\footnotetext{
${ }^{4}$ Nelson e Winter (1982, p. 466) ressaltam a proximidade dessa análise com a literatura de organização industrial.
} 
O Schumpeter de 1911, n'A Teoria do Desenvolvimento Econômico, destacava que a expectativa de lucros acrescidos derivados do maior poder de mercado é o determinante endógeno das inovações. ${ }^{5} \mathrm{O}$ Schumpeter de 1942, na obra Capitalismo, Socialismo e Democracia, de outra parte, ressaltava que o poder de mercado favorece as inovações, pois os oligopólios possuem mais recursos internos para investimentos em inovações (com tecnologias mais custosas e baseadas em ciência), enquanto o comportamento dos rivais é mais previsível. Para os oligopólios, a inovação é parte essencial da concorrência (um imperativo, portanto) (Scherer, 2007). No entanto, uma concentração excessiva (com menor pressão competitiva) poderia gerar menores incentivos às inovações.

A partir da análise de Schumpeter, os dois padrões básicos de inovações ou regimes tecnológicos das empresas foram classificados como de tipo Mark I (ou ampliador) e Mark II (ou de aprofundamento). O primeiro é um padrão de "destruição criadora", a partir de firmas que nunca inovaram antes, com baixas barreiras tecnológicas à entrada, com papel fundamental dos empresários e de novas firmas. O segundo é um padrão de "acumulação criadora", a partir de firmas que já possuem um histórico inovador, em que prevalecem grandes empresas já estabelecidas e existem maiores barreiras à entrada para novas firmas. Esse último, portanto, está relacionado positivamente com o grau de concentração das atividades inovadoras e com a estabilidade hierárquica das firmas inovadoras, e negativamente com a importância da presença de novos inovadores (Breschi; Malerba; Orsenigo, 2000; Nelson; Winter, 1982, parte V).

Esses regimes tecnológicos são definidos pela combinação de quatro fatores. Altas oportunidades tecnológicas significam que, para um dado montante de recursos aplicados, existe elevada probabilidade de ocorrência de inovações. A apropriabilidade das inovações represen-

\footnotetext{
${ }^{5}$ Schumpeter critica o "individualismo metodológico passivo" neoclássico e cria a visão de um "individualismo metodológico ativo" (Dopfer, 2007, p. 69). Ou seja, os indivíduos não apenas reagem a oportunidades dadas, mas promovem mudanças nas condições econômicas. Esse é o papel ativo do indivíduo inovador. De outra parte, na visão de Schumpeter, o desenvolvimento é um processo de mudança qualitativa das estruturas econômicas, no qual a história tem um papel relevante para a teoria econômica, via processos de path dependence e de lock in, em um arcabouço teórico evolucionário (Freeman; Soete, 1997, p. 31).
} 
ta a possibilidade de proteção contra imitação e, portanto, captura de lucros. A cumulatividade dos avanços tecnológicos representa a capacidade das inovações presentes gerarem um fluxo de inovações subsequentes. Por fim, a natureza do conhecimento subjacente às atividades inovativas que pode ser mais genérica, codificada, ou mais específica, tácita e complexa. Em geral, menores oportunidades tecnológicas, maiores condições de apropriabilidade, maior cumulatividade tecnológica e alta importância da ciência básica como fonte de inovações são fatores que favorecem o padrão inovativo de aprofundamento (Schumpeter Mark II). Ao contrário, altas oportunidades tecnológicas, menores condições de apropriabilidade e cumulatividade, maior importância relativa das ciências aplicadas e um maior papel das fontes externas de conhecimento são fatores que favorecem o padrão inovativo ampliador (Schumpeter Mark I) (Breschi; Malerba; Orsenigo, 2000).

Llerena e Oltra (2002) consideram a existência de diferentes estratégias inovativas por parte das firmas, o que gera resultados importantes sobre a estrutura do mercado e a dinâmica tecnológica. Em um modelo de duas estratégias coexistentes, existem dois tipos de firmas, as com estratégia cumulativa ( $C$-firms) e as com estratégia não cumulativa (NC-firms). As C-firms adotam uma estratégia interna de aprendizado por busca (learning by searching), enquanto as NC-firms usam uma estratégia de aprendizado de fontes externas, absorvendo conhecimento. Essas estratégias inovativas determinam a evolução da estrutura industrial. A estratégia das $C$-firms tende a gerar uma estrutura de mercado altamente concentrada, muito intensa em capital e em $\mathrm{P} \& \mathrm{D}$, enquanto a estratégia das $\mathrm{NC}$-firms tende a produzir um mercado muito menos concentrado/mais homogêneo. A coexistência entre as duas produz uma estrutura de mercado oligopolista, com um núcleo de poucas $C$ -firms e um grande número de NC-firms entrantes sobreviventes. Segundo Llerena e Oltra (2002), existe uma forte correlação, com mútua determinação, entre o tamanho das firmas e sua estratégia inovativa, com as $C$-firms ampliando seu estoque de capital e, por isso, possuindo altos e heterogêneos market shares, enquanto as $\mathrm{NC}$-firms (com menor estoque de capital) têm baixos e homogêneos market shares. Por fim, concluem que a diversidade de estratégias também tende a produzir uma melhor performance tecnológica da indústria como um todo. 
Essa análise também pode ser aplicada para o ciclo de vida das indústrias, podendo passar-se de um padrão Schumpeter Mark I para um padrão Schumpeter Mark II. No início da história de uma indústria, com tecnologia mudando rapidamente, alta incerteza e baixas barreiras à entrada, novas firmas são as maiores inovadoras, determinando a dinâmica industrial. Com a maturação dessa indústria, com trajetórias tecnológicas mais definidas, tornam-se mais importantes na concorrência fatores como economias de escala, curvas de aprendizado, barreiras à entrada e recursos financeiros. Assim, grande empresas com poder monopolístico assumem um papel mais relevante no processo inovativo. No entanto, havendo grandes descontinuidades tecnológicas, o padrão Schumpeter Mark II pode ser substituído por um padrão Schumpeter Mark I, com novas firmas focando sua atuação em novas tecnologias e novas demandas (Breschi; Malerba; Orsenigo, 2000, p. 389, nota 2).

\subsection{Aprendizado e crescimento}

$\mathrm{Na}$ abordagem neoschumpeteriana, o processo de aprendizado é fundamental para explicar a ligação entre a órbita microeconômica e o desempenho macroeconômico de um país. Nessa concepção, o conhecimento é o principal insumo produtivo, responsável pelas constantes inovações e pelo seu uso eficiente, sendo a empresa (onde se cria e se acumula conhecimento) o agente central da inovação. O aprendizado tecnológico e organizacional (e sua produção e transmissão) é determinado nas relações internas da empresa, entre indivíduos e desses com a empresa, e nas relações externas da empresa, entre essas e outras instituições.

O processo de aprendizado, ${ }^{6}$ com mecanismos de produção e transmissão de conhecimento, desenvolve competências e capacitações para a busca de soluções de problemas, por parte dos indivíduos e das organizações (Johnson; Lundvall, 2005; Bell; Pavitt, 1995). Ou seja, objetiva-se a substituição de rotinas inadequadas por outras que, tendo em vista

\footnotetext{
${ }^{6}$ São tipos de aprendizado, relacionados por diferentes autores, por exemplo: learningby-doing, leaning-by-operating, learning-by-changing, learning-by-training, learning-byhiring, learning-by-searching, learning-by-using, learning-by-interact, learning from advances in science and technology, learning from inter-industry spillover; individual, organizational and institutional learning (Bell, 1984; Malerba, 1992; Edquist, 2001).
} 
alterações do ambiente interno ou externo à empresa, deem respostas mais eficientes. Nesse sentido, o crescimento econômico está associado diretamente à maneira como as rotinas afetam o funcionamento das organizações (Nelson, 2002). ${ }^{7}$

Esse processo de aprendizado pode ser diferenciado entre passivo e ativo. No primeiro caso, seria automático e relativamente barato (o conhecimento como um bem comercializável), apropriado em uma reação adaptativa ao conhecimento já produzido e codificado. No segundo caso, trata-se de um processo evolutivo e idiossincrático, de difícil imitação, uma vez que é inseparável das particularidades de cada empresa. Essas empresas (os seus recursos humanos) capacitam-se a realizar avanços técnicos incrementais ou radicais, em um processo ativo, não automático e relativamente caro (envolvendo gastos em P\&D), com resultados mais ou menos incertos. Desse modo, não é suficiente o acesso ao conhecimento codificado para haver aprendizado ativo. Portanto, diferencia-se aquisição/utilização de tecnologia, e desenvolvimento de capacitação tecnológica (Bell, 1984; Bell; Pavitt, 1995).

Essa capacitação tecnológica, segundo Bell e Pavitt (1995), pode ser de quatro tipos, de acordo com a sua intensidade. Em um nível básico, seria relacionada a investimentos e pós-investimentos, com melhorias ou adaptações em processos, produtos, materiais e componentes. Em um nível mais elevado, com maiores contribuições em termos de mudança técnica, estaria relacionada à capacidade de interação com outras firmas e instituições e à capacidade de contribuição para o desenvolvimento de bens de capital.

O processo de aprendizado visa ao desenvolvimento de competências e capacitações. Hodgson (1999) observa que o conhecimento (tácito e codificado) não depende apenas da capacidade intelectual do indivíduo, mas de sua interação com outros em um determinado ambiente. O aprendizado é enraizado (embedded), dependente da trajetória (path dependent), interativo, cumulativo (no tempo) e, por-

\footnotetext{
${ }^{7}$ As rotinas podem ser entendidas, também, como possuidoras de um duplo caráter, enquanto obstáculos, e como guias para inovações. Nesse último sentido, as trajetórias tecnológicas são também rotinas para os processos inovativos incrementais. Em contrapartida, rotinas inadequadas, por sua inércia, são obstáculos para mudanças, mas também criam condições para mudanças radicais (Perez, 2007).
} 
tanto, evolutivo, tanto para as organizações quanto para os indivíduos no interior delas. Por ser esse processo de aprendizado um fenômeno coletivo, é necessário dotar os indivíduos de um ambiente favorável ao aprendizado e, por conseguinte, à inovação.

A criatividade tem um papel fundamental no processo inovativo. Assim, o aprendizado é uma condição imprescindível para a inovação, justamente porque exerce influência direta sobre o processo criativo. Ou seja, a inovação não é resultado de um processo aleatório, mas sim do aprendizado individual e, sobretudo, organizacional, com forte peso da interação.

Cohen e Levinthal (1989) destacam a existência de uma dupla face do processo de $\mathrm{P} \& \mathrm{D}$, a inovação e o aprendizado. $\mathrm{O}$ estoque de conhecimento de uma firma é função de seu investimento em P\&D e da sua capacidade de absorção do conhecimento existente (e que pode ser absorvido, de acordo com a taxa de transbordamento) no seu mercado e de outros mercados e de instituições extramercado. Nesse sentido, segundo os autores, as firmas não investem em $\mathrm{P} \& \mathrm{D}$ apenas para a produção direta de inovações, mas também para manter e desenvolver uma maior capacidade de identificar, assimilar e explorar o conhecimento externo disponível. Desse modo, ampliam seu estoque de conhecimento com uma maior capacidade de absorção (que é um tipo de aprendizado), expandindo sua capacidade de gerar inovações.

Na visão evolucionária, portanto, a inovação é entendida como resultado do processo de aprendizado. Tendo em vista que a geração de competências e de capacitações é condicionada pela interação entre os agentes econômicos e as instituições, a difusão do conhecimento, proporcionada pelo processo de aprendizado, passa a ter papel fundamental na determinação do desenvolvimento econômico. Nesse sentido, o processo de aprendizado, em seu sentido individual e, sobretudo, coletivo, tem se configurado como um elo entre a geração, o uso e a disseminação de inovações e o desenvolvimento econômico (Dosi, 1984). ${ }^{8}$

\footnotetext{
${ }^{8}$ A correlação entre aprendizado e desenvolvimento econômico, assim como entre aprendizado e Sistemas de Inovação (seção 3), é aprofundada no capítulo "Processo de aprendizado, acumulação de conhecimento e Sistemas de Inovação: a "coevolução das tecnologias físicas e sociais" como fonte de desenvolvimento econômico", deste livro.
} 


\subsection{Eficiência schumpeteriana e crescimento}

Dosi (1984, p. 402-3) classifica em três as forças básicas que atuam no sistema econômico, em termos macroeconômicos. A primeira refere-se às leis de ajuste interno do tipo clássico (ou ricardiano), com o uso da melhor tecnologia, que se mantém constante. A concorrência, a difusão tecnológica e a mobilidade do capital são forças que tenderiam a produzir eficiência, no sentido estático. A segunda diz respeito às leis de expansão quantitativa via demanda, tratadas pelos modelos keynesianos de crescimento, que associam maiores investimentos "autônomos" derivados do surgimento de novos produtos e mercados. A terceira refere-se às leis de transformação, com mudanças de longo prazo nas tecnologias, nos padrões de demanda e na estrutura produtiva. Dosi (1984) destaca que a tecnologia está relacionada a essas três forças, bem como as determina.

A mudança técnica provoca difusão interindustrial de inovações, o que produz impactos macroeconômicos, tanto em termos de oferta quanto de demanda agregada. O resultado é um aumento da eficiência sistêmica, com o crescimento da produtividade do trabalho. Isso porque ocorrem inovações e aperfeiçoamentos adicionais derivados da expansão das empresas inovadoras e das imitadoras. As empresas que adquirem e adotam bens de produção inovadores normalmente também promovem inovações maiores ou menores. Tal atitude cria novos mercados e amplia os existentes, o que estimula novos investimentos. Assim, a difusão tecnológica na produção e na demanda são fortemente interdependentes (Dosi, 1984, cap. 5).

A partir disto, Dosi, Pavitt e Soete (1990) classificam três conceitos de eficiência que devem ser analisados para a determinação do desempenho de longo prazo de um país. A eficiência alocativa (ou ricardiana) é estática, no sentido de gerar um ganho de uma vez por todas para a produtividade dos países, e está relacionada com as maiores taxas de lucro de curto prazo. A eficiência dinâmica de crescimento (ou keynesiana) é função da taxa de crescimento da demanda internacional. Por fim, a eficiência dinâmica inovativa (ou schumpeteriana) está relacionada com as taxas de crescimento da produtividade de longo prazo.

Dosi, Pavitt e Soete (1990) argumentam que, havendo a propriabilidade e cumulatividade nos avanços tecnológicos, economias de escala estáticas e dinâmicas, gaps tecnológicos e interdependências 
entre países em setores não comercializáveis, podem ocorrer importantes trade-offs entre eficiência estática e dinâmica. O critério de "eficiência alocativa" não seleciona a especialização em setores com maior potencial dinâmico de avanço tecnológico ou de economias de escala, de forma que podem ocorrer círculos virtuosos ou viciosos de avanço técnico. A especialização internacional tem um efeito dinâmico, pois as capacitações tecnológicas estão associadas aos processos de produção e de inovação atuais, os quais têm potenciais muito diferentes entre setores. Assim, as escolhas alocativas presentes determinam a direção e a taxa de inovações. Nesse sentido, o que se produz importa, pois existem setores com potencial inovativo e produtivo superiores a outros.

A “eficiência ricardiana” determina um padrão de especialização que é função das diferenças relativas de produtividade entre países. Sempre que essa diferença relativa é maior nos setores mais dinâmicos tecnologicamente (com maiores oportunidades tecnológicas), a "eficiência alocativa" está em conflito com a "eficiência schumpeteriana”. Dosi, Pavitt e Soete (1990) argumentam que esse trade-off entre eficiência alocativa e inovativa é proporcional a distância que cada país está da fronteira técnica, considerando que esta é mais dinâmica e penetrante.

A "eficiência ricardiana" e a "eficiência de crescimento" também estarão em conflito sempre que as elasticidades de demanda internacionais pelos produtos transacionados forem distintas entre países (o que é o caso geral), o que gera diferentes potenciais de crescimento compatíveis com o equilíbrio do balanço de pagamentos. De uma maneira mais simples, países podem se especializar "eficientemente" na produção de mercadorias com fraca dinâmica de demanda internacional, restringindo o seu potencial de crescimento. Como ressaltado por Palma (2004), o aumento da competitividade não garante catch-up, sendo necessário evoluir no comércio internacional segundo a dinâmica tecnológica das indústrias estratégicas em termos de variações da demanda internacional.

Nesses casos, os sinais de mercado sobre rentabilidade relativa para os agentes microeconômicos são contraditórios com os sinais de "eficiência em crescimento" e de eficiência inovativa. Por isso, podem emergir decisões que produzam resultados macroeconômicos subótimos ou nefastos, caso a decisão dos agentes privilegiar a alocação de recursos baseada no critério de "eficiência ricardiana", o que é racional, sob o ponto de vista microeconômico. Podem, portanto, surgir padrões de crescimento vir- 
tuosos ou viciosos. É mais provável que em países desenvolvidos os três critérios de eficiência coincidam em termos de sinais para o mercado. No entanto, em países aquém da fronteira tecnológica (que gera as maiores oportunidades de inovações e de crescimento da demanda), ao contrário, a eficiência alocativa pode conflitar com a eficiência dinâmica. Mais do que isso, é possível que, quanto maior for essa distância da fronteira tecnológica, maiores tendem a ser as diferenças entre os sinais de mercado que privilegiam a eficiência alocativa (que produz as maiores taxas de lucro de curto prazo). Isso penaliza esses países, pois as escolhas alocativas presentes influenciam (induzem) a direção e a velocidade da evolução futura das vantagens/desvantagens tecnológicas de um sistema econômico (Dosi; Pavitt; Soete, 1990, cap. 8). ${ }^{9}$

A assimetria dos sinais ao mercado dos três critérios de eficiência para países líderes (coincidente) e defasados (conflitante) ocorre pelo seguinte motivo: uma situação de alta oportunidade tecnológica (com elevado grau de apropriabilidade associado) funciona como um incentivo à inovação em países na fronteira técnica. No entanto, essa mesma situação de oportunidade funciona como um sinal negativo (uma barreira à entrada) em países distantes da fronteira técnica, e tanto mais negativo quanto maior essa distância. Ou seja, em cada país, os sinais são particulares e diferentes para a mesma oportunidade, pois eles refletem suas especificidades com relação a ativos e a capacitações. ${ }^{10}$ Isto tende a ampliar as defasagens, sendo provocado pela existência generalizada de cumulatividade ou de rendimentos crescentes nas atividades produtivas e tecnológicas (Baptista, 1997, cap. 3).

Além disso, com mudanças tecnológicas acentuadas, em fases de transição entre paradigmas tecnológicos, defasagens ou lideranças tecnológicas moldam sinais de lucratividade e alocação microeconômica de recursos, o que afeta o dinamismo econômico de longo prazo das economias. Surgem, nesses casos, oportunidades e também novas ameaças. Aparece ainda com mais importância a necessidade de políticas

\footnotetext{
${ }^{9}$ Há nestes aspectos uma clara correlação com a discussão entre os trade-offs entre flexibilidade de curto prazo e de longo prazo e entre flexibilidade individual e nacional (Chang, 2006, cap. 3).

${ }^{10}$ Esse mesmo raciocínio vale na comparação entre empresas na fronteira ou distantes da fronteira técnica (Dosi; Pavitt; Soete, 1990, cap. 8).
} 
que afetem os padrões dos sinais econômicos (como preços e rentabilidades relativos), sendo estas tanto mais essenciais quanto maior for a distância que separa o país da fronteira tecnológica. Trata-se, portanto, das há muito defendidas (como por Myrdal e Amsden) políticas para deixar os preços "errados" (Cimoli; Dosi; Nelson; Stiglitz, 2009, p. 31).

\section{Sistemas de Inovação (SIs)}

Na discussão sobre como as inovações surgem em um sistema econômico e sobre o que determina a capacidade competitiva internacional e o crescimento de um país, nasce a abordagem sobre Sistemas de Inovação (SIs) no final dos anos 1980. A base é o Schumpeter de 1942, mas também List, que já chamava a atenção, a partir do exemplo da Prússia, para questões relativas aos sistemas nacionais de produção. Por exemplo, em relação à interdependência de investimentos tangíveis e intangíveis, à importância de instituições de ciência e educação, e à correlação entre importação de tecnologias e desenvolvimento/ aprendizado técnico doméstico, antecipando, com isso, teorias contemporâneas sobre SIs (Lundvall, 2007).

A teorização parte de interpretações sobre a relação entre inovações e conhecimento (que é diferente de informação de agentes racionais), sobre o fato de que os agentes adquirem conhecimento (a) por seu esforço e (b) por transbordamentos de outros atores, de que as inovações e o aprendizado são dependentes do contexto; de processos interativos e estão enraizados na estrutura produtiva; e de que o crescimento econômico depende de sinergias extramercado. No processo de crescimento econômico existem (a) invenções, (b) inovações e (c) sua difusão, absorção e uso. A análise dos SIs foca o primeiro e o terceiro elementos, enquanto a atuação do empresário está mais no segundo, que é o foco do Schumpeter de 1911 (Carlsson, 2007; Lundvall, 2007; Freeman e Soete, 1997, cap. 12). Assim, um SI inclui todos os fatores econômicos, sociais, políticos, organizacionais e institucionais (e outros) que influenciam o desenvolvimento, a difusão e o uso das inovações (Edquist, 2005).

Os principais atores de um SI são as empresas, que investem em $\mathrm{P} \& \mathrm{D}$ e usam e fornecem tecnologias; o governo, com suas agências públicas, 
que formulam e executam políticas de ciência e tecnologia; e instituições, como universidades e centros de pesquisa, que podem ter maior ou menor apoio governamental. Esse conjunto de atores representa a "infraestrutura tecnológica" de um país, e sua ação integrada projeta o seu potencial de desenvolvimento.

Segundo Malerba (2003), a trajetória dos SIs é dependente de tecnologia, de conhecimento, de atores (governos, empresas, laboratórios, universidades etc.) e arranjos institucionais, sendo o foco da análise a interação dos atores econômicos, sociais e políticos, com o potencial de fortalecimento de capacitações e de difusão de inovações (Tigre, 2005).

Freeman e Soete (1997, cap. 12) destacam os aspectos institucionais do conceito. Para eles, um sistema de inovação (nacional, regional, local, tecnológico ou setorial) pode ser entendido como uma rede de instituições científicas e técnicas, dos setores público e privado, cujas atividades e interações geram, adotam, importam, modificam e difundem novas tecnologias, sendo a inovação e o aprendizado seus aspectos cruciais, levando em conta que esse ambiente social pode estimular, facilitar ou impedir inovações das firmas. Um SI é definido, portanto, por suas fronteiras, seus componentes, suas interrelações e os atributos dos componentes.

Pela forte relação dos Systems of Innovation (SIs) com o sistema educacional e o aprendizado em geral, foi desenvolvido o conceito de Sistemas de Aprendizado (Systems of Learning) (Edquist, 2001; Viotti, 2001). Ou seja, apesar da importância da P\&D, um conjunto de outros fatores também é fundamental na determinação das inovações, principalmente a incremental, como, por exemplo, o sistema educacional, o treinamento, a acumulação de conhecimento e a interação dos produtores com os usuários de tecnologia. Edquist (2001) ressalta que o "aprendizado individual" é fundamental para o "aprendizado organizacional”. Ou seja, o conhecimento e o aprendizado (individual e coletivo) são fundamentais para o processo de inovação. Por isso, são elementos fundamentais de um SI.

Um aspecto fundamental da análise evolucionária é o de que os elementos que explicam a dinâmica da mudança são de natureza tecnológica, organizacional e também institucional. Desse modo, é necessária a criação de condições organizacionais e institucionais, de forma simultânea e interrelacionada, para que as inovações tecnológicas sejam poten- 
cializadas. As próprias instituições estão sujeitas a inovações e possuem uma trajetória evolucionária. Portanto, essas inovações institucionais criam as condições para o desenvolvimento econômico, conjuntamente com as outras inovações ressaltadas originalmente por Schumpeter, em 1911. Em 1942, esse autor já apresentava outra formulação, com destaque para a incerteza e os aspectos institucionais do processo de "destruição criativa". Assim, as inovações teriam também uma dimensão institucional para a empresa e seu ambiente de interação. Ou seja, a forma como as diferentes inovações são combinadas condiciona o desempenho e a trajetória das economias (Chang, 2003a e 2007).

O surgimento de um pensamento econômico neoinstitucionalista, derivado do velho institucionalismo e em contraposição ao novo institucionalismo liberal (NEI), tornou patentes as aproximações deste com as elaborações teóricas evolucionárias. Surge, a partir daí, a possibilidade de uma abordagem conjunta chamada de "institucionalista-evolucionária”, que trata da coevolução das tecnologias, organizações e instituições, como já destacado por Richard Nelson (1996) (Cimoli; Dosi; Nelson; Stiglitz, 2009).

\section{Paradigmas tecnoeconômicos e ciclos de longo prazo ${ }^{11}$}

Freeman e Soete (1997, cap. 13) afirmam que as inovações e a acumulação de conhecimento, interagindo com a acumulação de capital, com economias de escala e com mercados em expansão, são os mais dinâmicos elementos determinantes de crescimento, pois geram oportunidades para novos investimentos, com fortes implicações macroeconômicas. A partir dessa dinâmica, poder-se-ia entender o crescimento desigual (processos de convergência ou divergência) entre países e ao longo do tempo, dependendo também de uma combinação entre mudanças técnicas e institucionais.

Nesse sentido, surgem novos conceitos no âmbito da teoria evolucionária. Segundo Carlota Perez (2002, cap. 2), "revoluções tecnológicas” são clusters de novas e dinâmicas tecnologias, produtos, indústrias

\footnotetext{
${ }^{11}$ Este tema também é desenvolvido no sexto capítulo desta publicação, "Padrões históricos da mudança tecnológica e ondas longas do desenvolvimento capitalista".
} 
e infraestruturas, que promovem modificações em toda a economia e geram desenvolvimento de longo prazo. Podem ser, por exemplo, novos insumos, fontes de energia, materiais, novos produtos e processos ou nova infraestrutura. Isso cria princípios tecnológicos e organizacionais genéricos, promovendo ampliação do potencial da produtividade para toda a economia (com a possibilidade de rejuvenescimento e upgrade das indústrias maduras), o que caracteriza o surgimento de um novo "paradigma tecnológico", com a generalização de novas práticas para empresários, administradores, inovadores, investidores e consumidores. Esses modelos ou padrões de solução de problemas a serem seguidos (uma nova fronteira de princípios que se torna senso comum) precisam ser socialmente aprendidos, enfrentando a inércia (a necessidade de desaprender "o velho"), o que exige tempo (Dosi, 1984, cap. 2). Esse desenvolvimento, portanto, não é um processo linear, ocorrendo em etapas, em surtos, significando modificações qualitativas na sociedade.

Uma característica importante desses novos paradigmas tecnológicos é a de que eles podem criar vantagens para newcomers, pois mudanças de paradigmas abrem "janelas de oportunidade" para processos de catch up e de ultrapassagens. No entanto, um excesso de inércia pode gerar atrasos. Portanto, a capacidade de mudança estrutural é uma habilidade social de alto valor ${ }^{12}$ (Perez, 2002, cap. 2).

Esses paradigmas tecnológicos determinam "trajetórias tecnológicas", ou padrões relativamente ordenados de mudanças, de atividades "normais" de resolução de problemas (Dosi, 1984, cap. 2). Os clusters de inovações radicais exigem não só mudanças na produção, mas também nas sociedades, instituições e organizações (Freeman e Soete, 1997, cap. 13). Assim, esses paradigmas tecnológicos (com suas bases hard, soft e ideológica) transformam-se em "paradigmas tecnoeconômicos" ${ }^{13}$ (Perez, 2002, cap.2).

\footnotetext{
${ }^{12}$ Gerschenkron (1973) já destacava, a partir do exemplo dos processos de catch-up dos países europeus, que o gap tecnológico é uma oportunidade para os países atrasados, mas requer esforços sustentados para sua realização. Abramovitz (1986), em contrapartida, destaca a possibilidade de falling behind de países que não conseguirem gerar certas capacitações que evitem retrocessos (Fagerberg, 2007). Fagerberg observa que algumas interpretações, mesmo não sendo de autores schumpeterianos, têm um "sabor" dessa escola. ${ }^{13}$ Dosi e Labini (2007) destacam as relações desse conceito com as análises sobre SIs e com a literatura da Escola da Regulação.
} 
Segundo os teóricos sobre ciclos econômicos, não existem apenas estágios ou períodos na história econômica, mas ondas ou ciclos, o que significa que são recorrentes. Uma crítica a essas concepções é a de que elas representariam a existência de determinismo tecnológico. Louçã (2007) argumenta que as sucessivas ondas longas não surgem desconectadas das atividades sociais e das instituições. Para esse autor, ocorrem recorrentemente vários fenômenos. Um deles é a repetição de sucessivas ondas longas de excepcionais oportunidades de lucros derivadas de inovações bem-sucedidas em certas atividades econômicas. ${ }^{14}$ Louçã, em sua interpretação, enfatiza, em vez dos fenômenos agregados, as mudanças estruturais e as divergências setoriais características das inovações-chave (fenômenos desagregados), as quais geram um "efeito demonstração" (com a alta taxa de lucro), o que estimula a sua difusão e generalização de aplicação.

Outro fenômeno característico das ondas longas é a ocorrência, não de poucas, mas de "constelações" de inovações técnicas e organizacionais interdependentes e que se apoiam mutuamente. Além disso, há a recorrência de ondas de mudanças organizacionais e administrativas nas empresas. De outra parte, sempre existem crises de ajustamento estrutural. ${ }^{15}$ Também aparecem modificações de regimes regulatórios sobre a tecnologia ou sobre a economia como um todo, tanto nacional quanto internacionalmente (comércio internacional), que são demandadas pelos novos setores líderes. Por fim, Louçã (2007) também destaca a recorrência de modificações sociais, políticas e culturais nas ondas longas, as quais estão relacionadas às alterações dos regimes regulatórios e às crises de ajustamento estrutural.

Silverberg (2007) observa que o destaque dado às questões sociais e políticas nos modelos schumpeterianos e regulacionistas possui uma semelhança com a visão de Marx sobre a relação entre a infraestrutura material (na qual a tecnologia é fundamental) e a superestrutura so-

\footnotetext{
${ }^{14}$ Ernest Mandel (1995), assim como outros autores marxistas, elaboram interpretações cujo fator determinante é a dinâmica da taxa "agregada" de lucro, em função do processo de inovações (Louçã, 2007).

${ }^{15} \mathrm{O}$ desemprego estrutural, com desajustes entre oferta e demanda de mão de obra, é manifestação da passagem de uma para outra onda longa.
} 
ciopolítica. Em Marx, as duas esferas precisam estar adequadamente correlacionadas, mas pode ocorrer descompasso, o que gera a necessidade de ajuste. Para Silverberg, na concepção evolucionária, parece que o paradigma-tecnoeconômico é determinante, e o social/político/ cultural se adapta, sendo determinado pelo primeiro.

O próprio Kondratieff já havia destacado a existência de ciclos de investimentos em infraestrutura. Esses processos já ocorreram várias vezes na história econômica, com inovações radicais de meios de transporte e de fontes de energia, por exemplo. Essas novas tecnologias criam necessidades de investimentos generalizados (e sincronizados) em outros setores correlacionados ou formam novos clusters produtivos. Isso suscita a possibilidade de grandes volumes de investimentos, o que produz fortes impactos agregados e mudanças estruturais com padrões determinados (Silverberg, 2007).

As inovações impactam a economia de forma agregada quando ocorre um processo de forte difusão. Por isso, um aumento considerável na produtividade média da economia necessita de certo tempo para se fazer sentir. Por outro lado, as inovações, para produzirem impactos agregados, precisam se transformar em demanda por bens de capital, o que gera efeitos multiplicadores e aumento de demanda efetiva (Silverberg, 2007).

Uma interpretação importante para explicar a não homogeneidade no tempo das inovações radicais foi elaborada pelo teórico Gerhard Mensch (1975). Em seu modelo, as inovações são adotadas ou não de acordo com a fase do ciclo. Quando o ciclo está ascendente, inovações radicais novas podem não ser adotadas, pois as antigas estão sendo satisfatoriamente lucrativas. Em situações de depressão, ao contrário, essas inovações originais podem ser adotadas, pois aí são necessárias para recuperar a rentabilidade.

Carlota Perez $(2002 ; 2007)$ apresenta um modelo sobre ondas ou surtos de desenvolvimento, ou paradigmas tecnoeconômicos, evitando o uso do termo "ciclos", tendo em vista a dificuldade de comprovação da homogeneidade desse processo. Mesmo com esse problema, o fato é que, segundo ela, ocorreram sucessivas revoluções tecnológicas na história, com a recorrência de certas dinâmicas (inclusive em relação à regularidade de duração, cerca de 40 a 60 anos) a partir do surgimento de tecnologias genéricas que modernizam a estrutura econômica como um todo. 
Para Schumpeter (1911), as inovações são baseadas na criação de crédito (função de emprestador) e na capacidade empresarial (função de tomador de empréstimo), como as duas faces da mesma moeda. No entanto, estranhamente, segundo Perez (2007), o verdadeiro "herói”, tanto em Schumpeter quanto nos neoschumpeterianos, é o empresário, aparecendo o banqueiro apenas como facilitador. $\mathrm{O}$ empresário é enfatizado, enquanto o agente financiador é negligenciado. Criticando essa interpretação, o modelo de Perez incorpora na análise a dinâmica do capital financeiro e suas relações com o capital produtivo e com as revoluções tecnológicas.

Segundo Perez (2002, cap. 5), as ondas/surtos (surge) de desenvolvimento possuem dois períodos: de instalação (installation) e de implantação (deployment) dos paradigmas tecnoeconômicos. Nos dois, ocorre a difusão das tecnologias da nova revolução tecnológica, sendo mais "forçada" (contra as rotinas do velho paradigma) no primeiro e mais coerente, enquanto senso comum, no segundo. No primeiro, o capital financeiro lidera, enquanto, no segundo, a liderança é do capital produtivo. Dividindo os dois períodos, ocorre um ponto de inflexão (turning point).

Esses dois períodos estão divididos em quatro fases. No primeiro período, de instalação, após o big-bang tecnológico, ocorrem a fase de irrupção e a fase especulativa (ou frenzy). No segundo, de implantação, tem-se a fase de sinergia e a de maturidade.

A fase de irrupção (o "tempo da tecnologia") começa em um contexto no qual o velho paradigma está maduro, com mercados saturados e desemprego (derivado da estagnação e da modernização anteriores), com deflação ou inflação (em função das condições institucionais) e envolto em um sentimento de impotência para trabalhadores e governos, pois suas políticas não mais funcionam adequadamente. Nesse contexto, existe ociosidade, sendo a mão de obra e os lucros de empresas do velho paradigma recursos potenciais para novos investimentos. Nessa situação, com empresas em busca de soluções, há necessidade de que ocorra algo novo. Ao mesmo tempo, também existem a oportunidade e as condições adequadas de custos (salários e taxas de juros baixos). Dessa maneira, historicamente surgiram inovações fundamentais (o big-bang), as quais estimulam iniciativas empresariais em massa, com grande potencial de crescimento da produtividade agregada, em decorrência de sua difusão e assimilação. 
Enquanto o capital produtivo, no contexto de maturidade da revolução tecnológica anterior, permanece mais rígido (é path-dependent em termos de investimentos em equipamentos, estruturas, conhecimento, experiência, organização e relações com fornecedores, distribuidores e clientes), o capital financeiro é muito mais flexível na alocação de recursos, podendo mudar rapidamente do velho para o novo paradigma, desde que tenha liberdade. Nesse contexto, o capital financeiro cumpre um papel fundamental ao realocar poupanças de setores ociosos para onde ele está sendo demandado. Na interpretação de Perez, o capital financeiro segue critérios similares ao do capital produtivo em seu processo inovador. Um setor financeiro flexível e inovador, que aceita financiar atividades de alto risco (inovações radicais) parece ser o mais adequado, pois o anterior, sendo rígido, não está dando conta das novas necessidades. Desse modo, o capital financeiro passa a exigir flexibilização, e isso parece ser adequado para o setor produtivo (Perez, 2007).

Assim, surgem novas oportunidades técnicas e de lucros em meio à estagnação, novos setores atraem investidores e novos produtos atraem consumidores. Ao mesmo tempo, a formação de clivagem tecnológica exige que velhos setores se modernizem. Além disso, o capital financeiro atende às necessidades de investimentos nessas inovações. Assim, existe, nessa primeira fase, um love affair do capital produtivo com o financeiro.

$\mathrm{Na}$ fase seguinte, especulativa (o "tempo da finança"), existe intenso investimento nas novas tecnologias, com forte geração de lucros, com possibilidade de excesso de investimentos e com criação de recursos superior à sua capacidade de absorção por investimentos reais. Essa renda financeira busca valorização, com formação de bolhas especulativas e inflação no mercado acionário. Assim, a finança se aparta da economia real. Ocorre tendência à dissociação das esferas produtiva e financeira, e o capital financeiro impõe seus interesses, com muita riqueza e exclusão social e extremo individualismo. Em contrapartida, o arcabouço regulatório torna-se impotente.

Ao mesmo tempo, o capital financeiro dirige um intenso acúmulo de novas infraestruturas e tecnologias, ocorre grande exploração de novas oportunidades técnicas e se fortalece a "livre" concorrência, com a criação de novos mercados e rejuvenescimento de velhas indústrias. Ao final dessa fase, o potencial do novo paradigma está fortemente ins- 
talado na economia. No entanto, concomitantemente geram-se tensões estruturais, que tornam essa fase insustentável.

Ocorre, neste momento, um processo de transição (turning point), com possibilidade de crash e recessão, pois a fase especulativa anterior é instável. Existe um desbalanceamento entre o potencial produtivo e a demanda existente, que aparece como saturação prematura do mercado. Na formulação de Perez, a dificuldade nesse momento não é tecnológica. Mudanças institucionais com intervenções do Estado na regulação do mercado são requeridas para passar da fase especulativa para a fase de sinergia, mas essa solução não é garantida, podendo ser rápida ou demorar anos, dependendo da consciência sobre a insustentabilidade da regulação anterior e dos interesses, da lucidez e do poder relativo das forças sociais participantes. As mudanças necessárias exigiriam também maior atenção aos interesses sociais, com intervenção do Estado, não por interesses ideológicos ou voluntaristas, mas porque as tensões precisam ser superadas, com a recomposição de condições adequadas para o crescimento. Fundamentalmente, o capital financeiro agora deve ser mais regulado, reconectando-se à esfera produtiva.

Com a superação dos problemas institucionais do turning point, surge uma fase de sinergia (o "tempo da produção"). Existem condições adequadas para crescimento, com a infraestrutura instalada (permitindo externalidades positivas) e os investimentos básicos realizados, derivando-se daí as possibilidades dinâmicas das economias de escala. Há possibilidades de pleno emprego e de melhor distribuição de renda, ou de uma "Idade de Ouro". Segundo Perez (2002), com as finanças como suporte do capital produtivo, o novo paradigma agora "governa supremo".

No entanto, necessariamente surge a fase de maturidade, o que significa que a difusão da tecnologia foi concluída para as principais indústrias. Com isso, ocorre gradual saturação dos mercados e menores oportunidades de investimentos, com aumento de desemprego e crescente frustração de expectativas. A produtividade cresce menos e os lucros diminuem. Ocorrem fusões, aquisições e migração de atividades para o exterior. Isso produz a necessidade de busca por novas soluções tecnológicas fora do paradigma existente, ou seja, a necessidade de novo big-bang, a partir do qual se retoma o ciclo. Nessas circunstâncias, podem coexistir dois paradigmas tecnológicos, um em declínio e outro em ascensão. 
Segundo Perez (2002), as passagens entre fases na história podem parecer contínuas e invisíveis para os contemporâneos. Além disso, existem diferenças importantes entre países. Portanto, a análise é realizada com forte estilização, com determinação de fases por interpretação e não por séries de dados.

Existem dificuldades para a comprovação da existência de ciclos longos via cálculos econométricos, por problemas de qualidade dos dados ou da própria existência de longas séries de dados. Por outro lado, dificilmente as técnicas econométricas conseguem detectar o fenômeno dos ciclos longos, ainda mais quando se espera que ele tenha um padrão de cerca de 50 anos. Portanto, a existência de fenômenos de ciclos longos com periodicidade média de 40 a 60 anos não tem comprovação econométrica. No entanto, Silverberg (2007) considera que não existem dúvidas sobre a existência de flutuações de longo prazo. Mesmo sem comprovação econométrica definitiva, a formulação teórica correlacionando inovações, difusão tecnológica, condições financeiras e capacidade empresarial inovadora, segundo esse autor, é altamente frutífera e foi derivada de pesquisas sobre ciclos longos.

\section{Tecnologia e inserção econômica internacional}

O comércio internacional tem sido um poderoso impulsionador de crescimento econômico, e existe forte evidência de que as melhores performances exportadoras estão associadas a inovações técnicas e organizacionais bem-sucedidas e seus impactos dinâmicos, pois elas determinam a competitividade de longo prazo. Segundo Dosi (1984, cap. 4), a capacidade exportadora de um país é função de sua capacidade de gerar inovações e/ou imitações, de forma rápida e criativa. No entanto, curiosamente, como observam Freeman e Soete (1997, cap. 14), as teorias sobre comércio internacional ortodoxas não incorporaram essas variáveis, com seus resultados cumulativos. ${ }^{16}$

\footnotetext{
${ }^{16}$ A vertente teórica neoclássica sobre comércio internacional, que centra sua análise na dotação dos fatores, tem tido seus pressupostos pouco realistas relaxados por vários modelos, inclusive para dar melhor tratamento à questão tecnológica. Por exemplo, nos modelos de Heckscher-Ohlin expandidos, que incorporam um fator de produção adicional (como trabalho qualificado versus não qualificado). Dosi, Pavitt e Soete (1990)
} 
Em contraposição às teorias baseadas em dotação de fatores (e suas extensões), a vertente interpretativa schumpeteriana enfoca a origem dos retornos crescentes, não na concorrência imperfeita em si, mas nas tecnologias produtivas e nas inovações, em geral, com seus impactos cumulativos, e também em elementos como path dependence/irreversibilidade dos processos (Arthur, 1994) e economias de aglomeração.

No comércio internacional, a ideia de eficiência alocativa exige que haja rendimentos constantes e pleno emprego, e que não haja externalidades ou economias de escala. Nesse caso, o comércio internacional livre será eficiente para todos os países, a partir de suas vantagens comparativas. O problema é que esses pressupostos não são base adequada para a teoria, pois são improváveis. Nesses contextos, os ajustes derivados das diferenças internacionais de preços, de produtividades e de tecnologia não são suficientes para garantir ganhos para os países no curto e no longo prazo (Kaldor, 1981). Para isso, é necessário comparar os efeitos da eficiência alocativa sobre a taxa de crescimento macroeconômico de longo prazo, compatível com o equilíbrio do balanço de pagamentos (a "eficiência keynesiana"), e sobre o dinamismo tecnológico (a "eficiência schumpeteriana"). Não há nada no mecanismo da eficiência alocativa garantindo que, ao mesmo tempo, serão alcançados os outros critérios de eficiência. Ou seja, é necessário analisar quais os efeitos da especialização derivados das vantagens comparativas sobre as "eficiências keynesiana e schumpeteriana", no caso de pressupostos ultrarrestritivos não existirem. ${ }^{17}$

Pressupostos importantes dessa interpretação são que as assimetrias de nível tecnológico e de capacidade inovativa de empresas e países são

consideram a "nova teoria do comércio internacional" como uma extensão nesse sentido, enquanto Freeman e Soete (1997) a consideram uma segunda vertente interpretativa, tendo em vista suas diferenças com os modelos anteriores. Essa última incorporou economias de escala e diferenciação de produtos como elementos geradores de retornos crescentes (vantagens de concorrência imperfeita), abrindo margem para a defesa da adoção de políticas estratégicas de comércio internacional. Krugman também incorpora mudança tecnológica endógena (como no seu modelo Norte-Sul), porém enfatizando o caráter de bens públicos dessas inovações.

${ }^{17}$ Esse tema é desenvolvido no capítulo "Padrões de eficiência no comércio: definições e implicações normativas", deste volume. 
determinantes para as exportações e importações, assim como o são para a renda do país; que o equilíbrio macroeconômico internacional tem determinação fraca, de forma que o comércio internacional possui fortes efeitos sobre a atividade econômica (dito de outra forma, o crescimento é constrangido pelo balanço de pagamentos); que a tecnologia não é um bem livre; e que os padrões de comércio internacional têm implicações dinâmicas de longo prazo, podendo essas ser "virtuosas" ou "perversas" (Dosi; Pavitt; Soete, 1990, cap. 2; Dosi, 1984, cap. 4).

Estendendo o modelo de criação de vantagens de monopólio derivadas das inovações para a economia internacional, chega-se à interpretação de um modelo baseado em technology gap. A difusão internacional das tecnologias eliminaria essas vantagens, de modo que seria necessária a criação continuada de inovações para a manutenção do gap tecnológico e as vantagens do país no comércio internacional (Fagerberg, 2007). O fluxo de comércio do país inovador para os demais se origina da existência de uma diferença positiva entre o nível de demanda e de produção do bem comercializado no país comprador, e esse fluxo de comércio é mantido em função da taxa de inovação do primeiro. Fatores como diferenciais de salários, proximidade, custos de transporte, adaptabilidade, mais a capacidade de aprendizado (ou tecnologia padronizada e internacionalmente disponível) podem erodir a vantagem do país inovador exportador depois de um tempo de defasagem. No caso de ciclos de vida muito curtos, com novos produtos entrando rapidamente no mercado, ou com taxas de mudança técnica alta, a vantagem do país inovador se manteria (Dosi, 1984, cap. 4).

Outra interpretação teórica importante é sobre o "ciclo do produto", com sua dinâmica de alocação da produção internacional (investimento externo direto) e do comércio internacional determinada pela estrutura dos mercados e de acordo com as características dos bens relacionados à sua diferenciação/padronização/grau de maturidade. Nesse modelo, os padrões de demanda induzem inovações por parte das firmas (Dosi; Pavitt; Soete, 1990, cap. 2).

O modelo de Thirlwall, apesar de keynesiano (considerando a demanda externa como uma força autônoma), poderia ser encaixado na linha teórica schumpeteriana em sua conclusão final, com a determinação tecnológica das elasticidades de demanda das exportações e das importações definindo os limites do crescimento econômico pelo constrangimento 
do Balanço de Pagamentos (Dosi; Pavitt; Soete, 1990, cap. 2). Fagerberg (2007) observa que essas elasticidades precisam ser explicadas (como Kaldor já apontara). Nesse sentido, cria um modelo (Fagerberg, 1988) com a inclusão de indicadores de competitividade (habilidade inovativa e capacidade de adaptação) nas equações de exportações e importações, transformando-o em um modelo schumpeteriano.

Freeman e Soete (1997) argumentam que nem esses modelos (de gap tecnológico, ciclo do produto e de Thirlwall), nem os modelos de Heckscher-Ohlin expandidos, conseguem identificar adequadamente as consequências cumulativas das inovações.

Com o atual processo de globalização, visões liberais consideram que teria aumentado ainda mais a tendência à convergência entre países ricos e pobres, pois a tecnologia seria mais móvel e as informações mais acessíveis, com custos de transmissão cadentes. Sanjaya Lall (2003) critica essa visão de que a tecnologia fluiria para países pobres que adotassem políticas liberalizantes. Segundo ele, as novas tecnologias não fluem assim, mas dependem de esforço, de acesso e de adaptação,_exigindo cada vez mais habilidades e capacidade organizativa, tornando-as mais difíceis para novos entrantes. Em compensação, as economias de escala e o aprendizado cumulativo tendem a fazer os investimentos se concentrarem em poucos locais, com externalidades ou determinantes de localização formando clusters.

Os dados mostram que o comércio internacional possui maior dinamismo em setores de alta tecnologia, o que demonstra a importância desse fator (Lall, 2003; Fagerberg, 1987). Além disso, há forte concentração das exportações industriais, em regiões e países, que aumentou com o tempo, indicando maiores barreiras. Isso é provocado pela realocação produtiva de empresas dos países ricos para os pobres, principalmente em atividades trabalho-intensivas, que está também correlacionada aos menores custos de transporte, à liberalização comercial e às políticas de atração de atividades exportadoras por esses países (Lall, 2003).

$\mathrm{Na}$ interpretação de Lall, a tecnologia em países em desenvolvimento depende de um processo evolucionário de construção de capacitações, o qual é difícil de criar e mudar. A simples liberalização não mudaria isso, e esse conhecimento é algo muito distinto do simples acesso à informação. Essa capacidade tecnológica é função de um processo de aprendizado que tem como características a incerteza (sem ple- 
na informação de todas as alternativas), a especificidade (com difícil transferência de capacitações), a cumulatividade (com a experiência e a imitação, não dependendo apenas de inovações complexas, mas de aprofundamento continuado), que é path-dependence, que possui externalidades e que depende de interações (aprendizado coletivo). Nesse sentido, são fundamentais a educação formal, o treinamento nas firmas e fora delas e o aprendizado no trabalho.

Dessa forma, a importação de tecnologias é necessária, mas não é substituto para desenvolvimento de capacidades, pois sua absorção depende da capacidade de aprendizado. Um país pode adquirir tecnologias prontas, mas pode não desenvolver capacidades (Bell; Pavitt, 1995). Além disso, não existe relação direta entre investimentos diretos externos (IDE) e capacitação técnica.

Um elemento determinante para o desempenho inovador e de comércio internacional é o fluxo de investimento externo direto e a participação das empresas multinacionais no país. Segundo a teoria "eclética" de Dunning, as diferenças internacionais de especialização e competitividade (tanto de empresas quanto de países) são função de economias de escala (tamanho), de aptidões inovadoras e imitadoras e do pioneirismo, de diferenciais de custos relacionados às curvas de aprendizado e da internalização das interdependências tecnológicas. Vários fatores levam uma empresa inovadora a definir por IDE em vez de por exportações em um determinado mercado. Ressaltam-se os custos de transporte ou diferenciais salariais, as diferentes características da demanda e de padrões de relacionamento entre usuários e produtores, a concorrência com as empresas domésticas do país receptor dos IDE com as outras multinacionais e a existência de tarifas e cotas de importação. Empresas podem se instalar também visando à maximização do seu crescimento, mesmo que a rentabilidade presente não seja ideal (DOSI, 1984, cap. 4). No entanto, esses IDE não significam que haverá criação de capacitações tecnológicas, apesar de certamente haver modernização da estrutura produtiva.

Enfim, a ocorrência de convergência ou divergência internacional dependeria do balanço entre forças que favorecem a acumulação de vantagens tecnológicas dos países avançados (com perpetuação de gaps tecnológicos) e das oportunidades de catch-up para a fronteira tecnológica, a partir de processos de difusão e imitação (Freeman; Soete, 1997, cap. 14). 


\section{Referências}

ACS, Z. J. Schumpeterian capitalism in capitalist development: toward a synthesis of capitalist development and the "economy as a whole". In: HANUSCH, H.; PYKA, A. (Editors). Elgar Companion to Neo-Schumpeterian Economics. Cheltenham, UK: Edward Elgar, 2007.

ABRAMOVITZ, M. Catching up, forging ahead, and falling behind. In: Thinking About Growth and Other Essays on Economic Growth \& Welfare. Cambridge: Cambridge University Press, 1989.

ARTHUR, W. B. Increasing Returns and Path Dependence in the Economy. Ann Arbor,USA: The University of Michigan Press, 1994.

BAPTISTA, M.A.C. A abordagem neo-schumpeteriana: desdobramentos normativos e implicações para a política industrial. Campinas: IE/Unicamp. Tese de doutoramento, sob orientação de Mário Possas, 1997.

BELL, M. "Learning" and the accumulation of industrial technology capacity in developing countries. In: FRANSMAN, M.; KING, K. (Orgs.) Technological capability in the third world. London: Macmillan Press, 1984.

BELL, M.; PAVITT, K. The development of technological capabilities. In: HAQUE, Irfan ul (Org.). Trade, Technology, and International Competitiveness. Washington: The World Bank, 1995.

BRESCHI, S.; MALERBA, F.; ORSENIGO, L. Technological regimes and schumpeterian patterns of innovation. The Economic Journal, 110, april, 2000.

CARLSSON, B. Innovation systems: a survey of the literature from a Schumpeterian perspective. In: HANUSCH, H.; PYKA, A. (Editors). Elgar Companion to Neo-Schumpeterian Economics. Cheltenham,UK: Edward Elgar, 2007.

CHANG, H. The market, the state and institutions in economic development. In: CHANG, H.(Ed.). Rethinking Development Economics. London: Anthem Press, 2003a.

The East Asian Development Experience: the miracle, the crisis and the future. Penang: TWN; New York: Zed Books, 2006.

. Understanding the relationship between institutions and economic development - some key theoretical issues. In: CHANG, Ha-Joon (Ed.). Institutional Change and Economic Development. New York: United Nations University Press, 2007.

CIMOLI, M.; DOSI, G.; NELSON, R. R.; STIGLITZ, J. Institutions and policies shaping industrial development: an introductory note. In: CIMOLI, M.; DOSI, G.; STIGLITZ, J. (Editors). Industrial Policy and Development: the political economy of capabilities accumulation. Oxford: Oxford University Press, 2009.

COHEN, W. M.; LEVINTHAL, D. A. Innovation and learning: the two faces of R\&D. The Economic Journal, 99, sept., 1989. 
CONCEIÇÃO, O. A. C. Crescimento econômico sob as óticas evolucionária e institucionalista: elementos para uma teorização apreciativa. In: DATHEIN, R. (Org.). Desenvolvimento Econômico Brasileiro: contribuições sobre o período pós-1990. Porto Alegre: Editora da UFRGS, 2008.

DOPFER, K. The pillars of Schumpeter's economics: micro, meso, macro. In: HANUSCH, H.; PYKA, A. (Editors.). Elgar Companion to Neo-Schumpeterian Economics. Cheltenham,UK: Edward Elgar, 2007.

DOSI, G. Mudança Técnica e Transformação Industrial: a teoria e uma aplicação à indústria dos semicondutores. Campinas: Editora da Unicamp, 2006.

DOSI, G. PAVITT, K. SOETE, L. The Economics of Technical Change and International Trade. New York: Harvester Wheatsheaf, 1990.

DOSI, G. LABINI, M.ro S. Technological paradigms and trajectories. In: HANUSCH, H.; PYKA, A. (Editors). Elgar Companion to Neo-Schumpeterian Economics. Cheltenham (UK): Edward Elgar, 2007.

EDQUIST, C. The systems of innovation approach and innovation policy: an account of the state of the art. DRUID Conference, Aalborg University, June 12-15, 2001.

. Systems of innovation: perspectives and challenges. In: FAGERBERG, J.; MOWERY, D. C.; NELSON, R.R. (Editors). The Oxford Handbook of Innovation. Oxford: Oxford University Press, 2005.

FAGERBERG, J. Structural changes in international trade: who gains, who loses? In: FAGERBERG, J., Technology, Growth and Competitiveness: selected essays. Cheltenham, UK: Edward Elgar, 2002.

. International competitiveness. In: FAGERBERG, J., Technology, Growth and Competitiveness: selected essays. Cheltenham, UK: Edward Elgar, 2002.

. Vision and fact: a critical essay on the growth literature. In: FAGERBERG, J. Technology, Growth and Competitiveness: selected essays. Cheltenham, UK Edward Elgar, 2002.

. The dynamics of technology, growth and trade: a Schumpeterian perspective. In: HANUSCH, H.; PYKA, A. (Editors). Elgar Companion to Neo-Schumpeterian Economics. Cheltenham, UK: Edward Elgar, 2007.

FREEMAN, C. A Schumpeterian renaissance? In: HANUSCH, Horst; PYKA, Andreas (Editors). Elgar Companion to Neo-Schumpeterian Economics. Cheltenham, UK: Edward Elgar, 2007.

FREEMAN, C.; SOETE, Luc The Economics of Industrial Innovation. Cambridge, USA: MIT Press, 1997.

GERSCHENKRON, A. Atraso Económico e Industrialización. Barcelona: Ediciones Ariel, 1973.

HODGSON, G. M. Evolution and institutions: on evolutionary economics and the evolution of economics. Cheltenham, UK: Edward Elgar, 1999. 
JOHNSON, B.; LUNDVALL, B-A. Promovendo sistemas de inovação como resposta à economia do aprendizado crescentemente globalizada. In: LASTRES, H. M. M.; CASSIOLATO, J. E.; ARROIO, A. (Orgs.). Conhecimento, sistemas de inovação e desenvolvimento. Rio de Janeiro: Editora UFRJ e Contraponto, 2005.

KALDOR, N. The role of increasing returns, technical progress and cumulative causation in the theory of international trade and economic growth. In: TARGETTI, F.; THIRLWALL, A. P. (Editors). The Essential Kaldor. New York: Holmes \& Meier, 1989.

LALL, S. Technology and industrial development in an era of globalization. In: CHANG, Ha-Joon (Editors). Rethinking Development Economics. London: Anthem Press, 2003.

LLERENA, P.; OLTRA, V. Diversity of innovative strategy as a source of technological preformance. Structural change and economic dynamics, 13, 2002.

LOUÇÃ, F. Long waves, the pulsation of modern capitalism. In: HANUSCH, H.;

PYKA, A. (Editors). Elgar Companion to Neo-Schumpeterian Economics. Cheltenham, UK: Edward Elgar, 2007.

LUNDVALL, B. National innovation systems: from List to Freeman. In: HANUSCH, H.; PYKA, A. (Editors). Elgar Companion to Neo-Schumpeterian Economics. Cheltenham, UK: Edward Elgar, 2007.

MALERBA, F. (Learning by firms and incremental technical change. The Economic Journal, v. 102, n. 413, p. 845-859, jul., 1992.

. Sectoral Systems and Innovation and technology policy. Revista Brasileira de Inovação, v. 2, n. 2, jul.-dez, 2003.

MANDEL, E. Long Waves of Capitalist Development: a Marxist interpretation. London: Verso, 1995.

MENSCH, G. Stalemate in Technology: Innovations overcome the depression. Cambridge (MA): Ballinger Publishing Company, 1975.

NELSON, R. As Fontes do Crescimento Econômico. Campinas: Editora da Unicamp, 2006.

Bringing institutions into evolutionary growth theory. Journal of Evolutionary Economics, n. 12, 2002.

NELSON, R.; WINTER, S. Uma Teoria Evolucionária da Mudança Econômica. Campinas: Editora da Unicamp, 2005.

PALMA, G. Gansos voadores e patos vulneráveis: a diferença da liderança do Japão e dos Estados Unidos, no desenvolvimento do Sudeste Asiático e da América Latina. In: FIORI, J. L. (Org.). O Poder Americano. Petrópolis: Vozes, 2004.

PEREZ, C. Technological Revolutions and Financial Capital: the dynamics of bubbles and golden ages. Cheltenham,UK: Edward Elgar, 2002. 
PEREZ, C. Finance and technical change: a long-term view. In: HANUSCH, H.; PYKA, A. (Editors). Elgar Companion to Neo-Schumpeterian Economics. Cheltenham,UK: Edward Elgar, 2007.

POSSAS, M. Ciência, tecnologia e desenvolvimento: referências para debate. In: CASTRO, A. C. et al. (Orgs.). Brasil em desenvolvimento 1: economia, tecnologia e competitividade. Rio de Janeiro: Civilização Brasileira, 2005.

SCHERER, F. M. Schumpeter and the micro-foundations of endogenous growth. In: HANUSCH, Horst; PYKA, Andreas (Editors). Elgar Companion to Neo-Schumpeterian Economics. Cheltenham,UK: Edward Elgar, 2007.

SCHUMPETER, J. A Teoria do Desenvolvimento Econômico. São Paulo: Abril Cultural, 1982. Coleção Os Economistas. . Capitalismo, Socialismo e Democracia. Rio de Janeiro: Zahar, 1984, .

SILVERBERG, G. Long waves: conceptual, empirical and modeling issues. In: HANUSCH, H.; PYKA, A. (Editors). Elgar Companion to Neo-Schumpeterian Economics. Cheltenham, UK: Edward Elgar, 2007.

TIGRE, P. B. Paradigmas tecnológicos e teorias econômicas da firma. Revista Brasileira de Inovação, v. 4, n. 1, jan./jun, 2005.

VERSPAGEN, B. Innovation and economic growth. In: FAGERBERG, J.; MOWERY, D. C.; NELSON, R. R. (Editors). The Oxford Handbook of Innovation. Oxford: Oxford University Press, 2005.

VIOTTI, E.B. National Learning Systems: A new approach on technical change in late industrializing economies and evidences from the cases of Brazil and South Korea. Science, Technology and Innovation Discussion. Paper n. 12. Cambridge, USA: Center for International Development, Harvard University, 2001. 